\title{
The psychological effects of centrality bias: an experimental analysis
}

\author{
Irene $\operatorname{Trapp}^{1} \cdot$ Rouven $^{T_{r a p p}}{ }^{2}$ (D)
}

Published online: 19 April 2018

(C) The Author(s) 2018

\begin{abstract}
This paper examines the psychological mechanisms that are activated by centrality bias in the context of subjective performance evaluation. Centrality bias refers to compressed evaluations of subordinates, implying that the variance in the performance of the evaluated employees is higher than the variance in the rewards determined by the superior. Based on insights from the social psychology literature, we argue that centrality bias may trigger different psychological mechanisms which affect the subordinates' willingness to exert work effort. We propose that these effects differ depending on whether employees are above-average or below-average performers. In line with our predictions, we detect a considerable asymmetry in the effects of centrality bias. In particular, we find that the relationship between centrality bias and the willingness to exert work effort is negatively mediated by controlled motivation and procedural fairness perceptions for above-average performers. For below-average performers, we find that centrality bias is positively related to procedural fairness perceptions which are, however, unrelated to the willingness to exert work effort. In addition, we shed light on the role of peer information and find that its disclosure has not a significant impact on the psychological mechanisms at work.
\end{abstract}

Keywords Autonomous motivation - Centrality bias · Controlled motivation · Procedural fairness $\cdot$ Subjective performance evaluation

JEL Classification M41 $\cdot$ M52

Rouven Trapp

r.c.trapp@rug.nl

1 Department of Accounting and Management Control, TU Dortmund University, 44221 Dortmund, Germany

2 Department of Accounting, University of Groningen, P.O. Box 800, 9700 AV Groningen, The Netherlands 


\section{Introduction}

The objective of this paper is to advance our knowledge on the behavioural implications of centrality bias. For this reason, we illuminate the psychological mechanisms that are activated by compressed subjective performance evaluations. Subjectivity in the context of performance evaluation has gained considerable momentum in recent years due to the shortcomings of objective performance measures (Ahn et al. 2010; Bol 2011; Cheng and Coyte 2014; Voußem et al. 2016). In particular, objective measures may be insensitive to employees' actions, incongruent with organizational objectives, noisy concerning uncontrollable factors or incomplete with regard to an employee's performance (Bol 2008; Rajan and Reichelstein 2006; Woods 2012). Subjective adjustments to objective performance measures made by the superior during the determination of monetary rewards may mitigate these shortcomings (Dai et al. 2018; Höppe and Moers 2011). ${ }^{1}$ Correspondingly, empirical evidence suggests that monetary rewards which are based on subjective assessments have a positive impact on pay satisfaction, productivity and profitability (Gibbs et al. 2004).

However, a potential drawback of subjective performance evaluation is its inherent discretion (Ittner et al. 2003; Moers 2005; Van der Stede et al. 2006). Prior research indicates that subjective performance evaluation often implies inaccuracies due to systematic measurement errors (Ahn et al. 2010; Bol 2011), suggesting that performance assessments by superiors are biased. In this context, leniency bias and centrality bias are two frequently observed patterns (Bol 2011; Frederiksen et al. 2017; Moers 2005; Prendergast 1999). ${ }^{2}$ Leniency bias is the tendency to inflate performance rewards, whereas centrality bias leads to compressed ratings. As the result of the latter, the variance in the ratings by the superior is lower than the variance in the performance of the evaluated employees (Bol 2008; Golman and Bhatia 2012). In other words, performers below (above) the average receive a higher (lower) reward than they are actually entitled to according to their performance (Bol et al. 2016). From a superior's perspective, it may be situationally rational to provide biased rewards. For instance, leniency bias may occur because the superior cares about the well-being of his subordinates or intends to avoid costs arising out of negative evaluations (Frederiksen et al. 2017; Kampkötter and Sliwka 2016). A lower differentiation of evaluations, as implied by centrality bias, may result from a superior's inequality aversion or imprecise signals regarding the subordinates' individual performance. It may also alleviate within-team competition and promote cooperation (Kampkötter and Sliwka 2016, 2017).

\footnotetext{
1 In addition to subjective adjustments to objective performance measures, such as discretionary discounts or premiums by a superior (Cheng and Coyte 2014; Woods 2012), subjective performance evaluation may refer to assessments of specific performance dimensions, which cannot be measured objectively (i.e., work attitude or interpersonal skills), based on a superior's personal impressions and opinions (Hartmann et al. 2010; Van der Stede et al. 2006). In line with prior research, this paper focuses on subjective adjustments to objectively measured performance for the determination of monetary rewards as this kind of subjectivity is frequently part of compensation contracts (Höppe and Moers 2011; Ederhof 2010).

${ }^{2}$ We acknowledge that subjective performance evaluation may be subject to further biases, such as halo effects (Bol 2008; Prendergast 1999). Yet, centrality bias and leniency bias are those that receive particular attention in the literature (Bol 2011; Moers 2005).
} 
Irrespective of these arguments, prior research stresses the adverse effects of centrality bias as predicted by economic theory (Baker et al. 1988; Prendergast 1999). Empirical evidence on the effects of centrality bias is scarce, potentially due to the lacking availability of corresponding company data sets and difficulties in getting access to them. However, the few exceptions that investigate the effects of centrality bias empirically tend to suggest that it is negatively associated with performance improvements (Ahn et al. 2010; Berger et al. 2013; Bol 2011; Engellandt and Riphahn 2011). This stream of research argues - in line with economic theory-that performance evaluations which are subject to centrality bias neither reward performance improvements nor sanction performance deteriorations adequately. As a consequence, individuals are expected to neglect performance enhancing efforts (Ahn et al. 2010).

This perspective, however, does not account for the full complexity of human behaviour which is not one-dimensionally motivated by external mechanisms. In this paper, we therefore argue-based on insights from the social psychology literature - that centrality bias may activate different psychological mechanisms with opposing behavioural implications. Correspondingly, we explore the different psychological mechanisms that may be triggered by centrality bias and shed light on their net effect. More precisely, we analyse whether the relationship between centrality bias and the willingness to exert work effort is mediated by controlled motivation and autonomous motivation - two types of motivation distinguished by selfdetermination theory - and by procedural fairness perceptions. Given that previous research has focused on the relationship between centrality bias and subsequent performance, we intend to open the intermediate "black box" by shedding light on the different psychological mechanisms that may explain prior empirical findings. An implicit idea inherent in this study is that the behavioural implications of centrality bias might be less uncontested than suggested by the prior literature. Indeed, this idea is reflected by Kampkötter and Sliwka (2017). Their findings suggest that differentiation (which implies the absence of a centrality bias) in performance appraisals is situationally related to lower subsequent performance. This finding challenges the prevailing notion that centrality bias has adverse effects per se.

In addition to opening the "black box" of psychological mechanisms, our paper emphasizes two particularities that may affect the behavioural implications of centrality bias: With the exception of Bol (2011), prior research usually does not take into consideration that the effect of centrality bias is likely to differ for aboveaverage performers as compared to below-average performers. Therefore, we take this differentiation into account and investigate the psychological mechanisms activated by centrality bias separately for above-average and below-average performers. Moreover, prior research mostly measures centrality bias based on individual sequences of performance appraisals and assumes that employees adapt their efforts as they anticipate future evaluations based on past rewards (Kampkötter and Sliwka 2017). In these studies, employees are usually not aware of whether the rewards of their peers are to the same degree subject to bias. In fact, the tendency to undervalue above-average performers and to overvalue below-average performers implies an unequal treatment of employees, suggesting that employees are to different degrees affected by centrality bias. According to insights from the social psychology 
literature, awareness or unawareness of the varying degrees to which employees are affected by centrality bias may have an impact on the psychological mechanisms and their behavioural implications. Against this background, we study how the availability of peer information, which unveils that above-average performers (below-average performers) are systematically undervalued (overvalued), is related to the psychological mechanisms activated by centrality bias.

We investigate our research questions and hypotheses in a vignette experiment with 425 students enrolled in a German university. Vignette experiments present participants a constructed description of a situation and capture their intentions and attitudes (Aguinis and Bradley 2014). In the present study, the participants faced a hypothetical work situation and were asked to complete a questionnaire which informs us about their willingness to exert work effort, their controlled and autonomous motivation and fairness perceptions. In line with our theoretical expectations, we detect a considerable asymmetry in the effects of centrality bias. More precisely, we find that centrality bias is significantly and negatively related to the willingness to exert work effort for above-average performers, but unrelated for below-average performers. With regard to the psychological mechanisms, we find that the relationship between centrality bias and the willingness to exert work effort is mediated by controlled motivation and procedural fairness perceptions for above-average performers. We detect a direct effect of procedural fairness perceptions on the willingness to exert work effort and an indirect one via autonomous motivation. For belowaverage performers, we find that centrality bias is positively related to procedural fairness perceptions which are, however, unrelated to the willingness to exert work effort. Interestingly and opposing to our predictions, we find that the disclosure of peer information has not a significant impact on the psychological mechanisms at work. Taken together, our study provides insights into the behavioural implications of centrality bias that go beyond the suggestions by economic theory. In this way, we complement the prior literature on centrality bias which mostly assumes negative effects on work effort and therefore focuses on its determinants (Bol 2011; Bol et al. 2016; Breuer et al. 2013; Chen 2014; Moers 2005; Woods 2012).

This paper is structured as follows. In Sect. 2, we develop our research questions and hypotheses based on insights from the social psychology literature. In Sect. 3, we describe the experimental procedure. We present our findings in Sect. 4 and discuss them in Sect. 5.

\section{Hypotheses and research questions}

\subsection{Background}

We explore the psychological mechanisms activated by centrality bias based on a hypothetical work situation, in which a superior determines a bonus for five subordinates to compensate their work effort. ${ }^{3}$ While an objective measure of work effort

\footnotetext{
${ }^{3}$ A more comprehensive description of our experimental design is provided in Sect. 3.1.
} 
is available for bonus assessment, the superior may discretionarily adjust the financial rewards. If the superior makes use of his discretion, a centrality bias emerges in our setting. We are interested in how these subjective adjustments affect the subordinates' willingness to exert work effort in the future period. In this context, the following lines of reasoning rely on two main ideas: First, we assume that the behavioural implications of centrality bias may depend on whether a subordinate has performed below or above the average. Second, we expect that the behavioural response also depends on whether a subordinate has not only information about his own reward, but also about the rewards of his peers ("peer information"). Based on insights from the social psychology literature, we thus discuss in the following the mediating role of different psychological mechanisms and the moderating role of peer information.

\subsection{The mediating role of controlled motivation}

Unlike traditional economic theory, which assumes that individuals are solely extrinsically motivated, self-determination theory provides a typology of different motivation types. A core idea of self-determination theory is the distinction between controlled and autonomous motivation (Gagné and Deci 2005). Both types of motivation are expected to increase the willingness to exert work effort (Kunz 2015). Controlled motivation is, in line with the assumptions of economic theory (Bonner and Sprinkle 2002; Eisenhardt 1989), regulated by external mechanisms, such as monetary rewards (Kunz 2015; Zapata-Phelan 2009). Correspondingly, we assume that an individual's controlled motivation is likely to be higher when performance-contingent monetary rewards are offered as compared to a situation in which no rewards are provided (Bonner and Sprinkle 2002; Kunz and Pfaff 2002). The motivational effect of monetary rewards is likely to be highest when there is a direct relationship between an individual's effort and the evaluation outcome. Centrality bias, however, mitigates this relationship (Prendergast 1999). Due to deflated performance evaluations, aboveaverage performers (below-average performers) receive a lower (higher) reward than they would receive based on their effort. Moreover, an increase in effort leads to a disproportionally low increase in monetary rewards (Berger et al. 2013; Bol 2011). Against this background, inducing more effort does not "pay off" adequately. If an individual is subject to centrality bias, we thus expect that the impact of monetary rewards on controlled motivation decreases, given that a marginal decline in effort is likely to imply a disproportionally low decline in rewards (Golman and Bhatia 2012). Therefore, we expect that above-average as well as below-average performers who are subject to centrality bias have less controlled motivation to exert work effort. Correspondingly, we formulate the following hypothesis $(\mathrm{H}):^{4}$

\footnotetext{
${ }^{4} \mathrm{We}$ assume that motivation as well as the fairness perceptions discussed in Sect. 2.4 are positively related to the willingness to exert work effort. Therefore, our hypotheses 1-3 imply a mediation. In other words, we predict that the relationship between centrality bias and effort is mediated by motivation and fairness perceptions, respectively. Given that prior research has accumulated a comprehensive body of literature indicating that motivation and fairness perceptions are positively related to effort and performance (Bonner and Sprinkle 2002; Colquitt et al. 2001), we focus on the psychological mechanisms activated by centrality bias and do not state the mediations explicitly.
} 


\section{H1: Centrality bias is negatively related to controlled motivation.}

\subsection{The mediating role of autonomous motivation}

According to self-determination theory, an individual's actions are not entirely driven by external mechanisms such as monetary rewards. Instead, it suggests that individuals are also autonomously motivated to engage in a task because of enjoyment or identification with the value and meaning that an activity implies (Gagné et al. 2015). ${ }^{5}$ Self-determination theory states that autonomous motivation is influenced by the satisfaction of three basic psychological needs-autonomy, competence and relatedness (Deci and Ryan 2000; Van den Broeck et al. 2010). The need for autonomy reflects an individual's need to feel self-determined and to have possibilities of choice (Deci and Ryan 2000; Gagné and Deci 2005). The need for competence refers to the experience of success in performing tasks and attaining intended outcomes (Deci et al. 2001). The need for relatedness captures the need to feel connected to others (Deci and Ryan 2000).

Self-determination theory argues that autonomous motivation can be influenced via contextual factors that address these psychological needs. According to Gagné and Forest (2008), compensation systems represent one of these contextual factors. In particular, the provision of rewards may derogate the feeling of autonomy as they put individuals under pressure to achieve a particular target and make them feel restricted in their decision-making about which actions need to be performed (Deci and Ryan 2000; Kunz and Linder 2012). At the same time, such rewards positively impact the feeling of competence as they imply feedback on an individual's task performance and goal attainment (Deci et al. 2001; Gagné and Forest 2008).

We argue that centrality bias may influence the satisfaction of these needs and thus expect autonomous motivation to mediate the relationship between centrality bias and the willingness to exert work effort. Previous research suggests that positive feedback is able to enhance the feeling of competence (Deci and Ryan 2000). In presence of a centrality bias, below-average performers receive an inflated reward. The corresponding overvaluation of their work effort may be perceived as a recognition, signalling success in performing the evaluated task and thus contributing to the feeling of competence. In contrast, above-average performers receive a deflated reward. This "undervaluation" may be perceived as negative feedback, suggesting that a task is not successfully performed. Therefore, centrality bias is likely to decrease the feeling of competence for above-average performers.

With regard to autonomy, we argue that the clouding of the link between an individual's effort and the resulting reward may be perceived as a restriction of autonomy. If individuals strive for a particular outcome, they can be less sure on whether their choices of action yield the intended outcome, given that the performance evaluation is less sensitive to their actual work. The mitigation of the linkage between

\footnotetext{
5 This assumption does not imply that performance evaluations and corresponding rewards are obsolete as individuals may not be sufficiently autonomously motivated to exert work effort. For this reason, we consider controlled and autonomous motivation as complements rather than substitutes.
} 
effort and reward may therefore diminish the feeling of having possibilities of choice. We predict that this adverse effect of centrality bias applies to above-average as well as below-average performers likewise.

Concerning the feeling of relatedness, the literature suggests that it is satisfied, for instance, when superiors appear caring (Deci and Ryan 2000). ${ }^{6}$ Against this background, below-average performers may interpret their disproportionally high reward as "distal support" (Deci and Ryan 2000, p. 235) for their efforts that may contribute to the feeling of a close connection with the superior. In contrast, above-average performers may perceive the disproportionally low reward as a signal of personal distance and lack of sufficient acknowledgement. Therefore, centrality bias may mitigate the feeling of relatedness on part of above-average performers. Taken together, we expect that centrality bias decreases the satisfaction of all three psychological needs for above-average performers, leading to the following hypothesis:

\section{H2: Centrality bias is negatively related to autonomous motivation of above-average performers.}

For below-average performers, we argue that the feeling of autonomy is likely to decrease, whereas the feelings of competence and relatedness may increase. Depending on how these effects outweigh, there might be a positive or negative relationship or no association at all. Given that the presence and the sign of the relationship are unclear ex ante, we pose the following research question (RQ):

RQ1: How is centrality bias related to autonomous motivation of below-average performers?

\subsection{The mediating role of procedural fairness perceptions}

Previous research suggests that the perceived fairness of performance evaluation is another psychological mechanism that influences individual behaviour as it affects work-related attitudes and outcomes (Burney et al. 2009; Lau and Tan 2006). Empirical evidence indicates that employees are more committed to work and perform better in their tasks if they perceive performance evaluations as fair (Colquitt et al. 2001). Correspondingly, we predict a positive relationship between the perceived fairness of performance evaluation and the willingness to exert work effort. With regard to fairness perceptions, the management accounting literature distinguishes two dimensions of fairness: distributive fairnesswhich refers to the perception of the distribution of outcomes among employees (Burney et al. 2009) — and procedural fairness — which reflects the perceived fairness of procedures that are used in the context of performance evaluation (Burney et al. 2009; Voußem et al. 2016). Given that our paper refers to bias as part of the

\footnotetext{
6 The feeling of relatedness does not only refer to the relationship between a subordinate and his superior, but may also affect the relationships among subordinates (Gagné and Deci 2005). We take the latter into consideration when we refer to the moderating role of peer information (see Sect. 2.5), which is likely to have an impact on the feeling of relatedness among subordinates.
} 
performance evaluation process, we focus on the procedural fairness of the performance evaluations (Hartmann and Slapničar 2012b).

In a recent paper, Voußem et al. (2016) analyse the relationship between subjective performance measures and fairness perceptions. They detect an inverted U-shaped relationship implying that subjectivity in performance evaluations increases the perceived fairness if the weight placed on the subjective measures is low. If a higher weight is placed on subjective performance measures, however, subjectivity decreases fairness perceptions. These findings support their line of reasoning that subjective performance measurement implies costs and benefits. They argue that, as the emphasis on subjectivity increases, the marginal benefits are likely to decrease, whereas the marginal costs increase. Voußem et al. (2016) consider biased evaluations as part of the costs of subjective performance evaluations. However, the relationship between centrality bias and procedural fairness perceptions has not yet been investigated explicitly.

Our prediction for the relationship between centrality bias and procedural fairness perceptions draws on referent cognitions theory which argues that individuals rely on reference comparisons in assessing fairness (Cropanzano and Folger 1989; Goldman 2003). More precisely, this theory suggests that individuals reflect on performance evaluation outcomes by generating mental simulations and comparing the actual outcome with a potential outcome that relies on a procedure, which is considered to be valid (McFarlin and Sweeney 1992; van den Bos and van Prooijen 2001). If the potential outcome is more favourable and the procedure used to determine the actual outcome appears less valid, individuals are expected to feel treated unfairly. We suggest that such comparisons appear particularly likely in situations in which the superior has the discretion to adjust an objective measure. In this setting, we expect that the potential outcome based on the objective measure without adjustments is likely to serve as a reference. In presence of a centrality bias, above-average performers receive a reward that falls short of the unbiased evaluation. Therefore, we expect that above-average performers consider the process underlying the biased outcome unfair and penalize it with lower effort.

\section{H3: Centrality bias is negatively related to procedural fairness perceptions of} above-average performers.

For below-average performers, the actual outcome is more favourable than the potential one according to the objective performance measure, suggesting that the superior applies a benevolent appraisal procedure. At the same time, the procedure for determining the reward is not discernible for the subordinate and thus may be perceived as less valid. In particular, below-average performers cannot rule out that the procedure will put them at a disadvantage in the future, even though they currently benefit from it. Due to this ambiguity inherent in the relationship between centrality bias and procedural fairness perceptions for below-average performers, there might be a positive or negative relationship or no association at all. For this reason, we pose the following research question: 
RQ2: How is centrality bias related to procedural fairness perceptions of belowaverage performers?

The aforementioned lines of reasoning suggest a direct relationship between procedural fairness perceptions and the willingness to exert work effort. However, the prior literature also provides arguments and corresponding evidence for an indirect effect: Procedural fairness perceptions may be positively related to autonomous motivation (Hartmann and Slapničar 2012a; Zapata-Phelan 2009). In particular, an evaluation process that is perceived as fair (unfair) may enhance (mitigate) the feeling of relatedness with the superior. This argument is in line with the reasoning by Cugueró-Escofet and Rosanas (2013) that procedural fairness perceptions may lead to a sense of belonging and thus may improve the feeling of relatedness with the superior. In addition, procedural fairness perceptions may be stronger when rewards reflect organizational objectives more clearly, implying lower ambiguity for an individuals' work role (Hartmann and Slapnicar 2012a, b). Such perceptions may reinforce the feeling of competence and thus imply a positive relationship between procedural fairness perceptions and autonomous motivation. Taken together, we suggest that fairness perceptions may affect the willingness to exert work effort directly as well as indirectly via autonomous motivation. In the findings section, our data analysis will consider both options.

\subsection{The moderating role of peer information}

Prior research does not take into consideration whether the individuals who are subject to a centrality bias are aware of the degree to which their peers are affected (Bol 2011; Engellandt and Riphahn 2011; Kampkötter and Sliwka 2017). However, theoretical insights suggest that peer information may have an impact on the association of centrality bias with autonomous motivation as well as with procedural fairness perceptions. For this reason, we discuss the moderating role of peer information in the following.

Social comparison theory suggests that individuals compare themselves with peers when the outcome of performance evaluations is available-even when they are not competing for a tangible outcome (Luft 2016; Tafkov 2013). Empirical evidence suggests that the disclosure of rankings motivates individuals to exert more work effort and to improve their performance relative to others (Hannan et al. 2013; Newman and Tafkov 2014). However, in the case of centrality bias, we argue that the disclosure of peer information is likely to decrease the impact of an employee's autonomous motivation to exert work effort. In presence of centrality bias, the provision of peer information reveals a systematic measurement error if information on actual work effort is available. Correspondingly, below-average performers are likely to recognize that their inflated reward is not driven by a specific acknowledgement or a close relationship with their superior. ${ }^{7}$ Moreover, the overvaluation

\footnotetext{
7 Note that peer information reveals the "source" of the bias to the subordinate. While the subordinate perceives "some bias" in absence of peer information, the provision of peer information enables him to perceive centrality bias as such. Therefore, the hypotheses on peer information relates to what changes a subordinates' perception of the bias. We are grateful to an anonymous reviewer for pointing this out.
} 
of their performance as well as the undervaluation of above-average performers may imply that the relatedness among subordinates decreases. For this reason, we expect that the enhancement of the feelings of competence and relatedness due to inflated ratings - as suggested in Sect. 2.3 - is mitigated.

Similarly, above-average performers get to know that their peers with a belowaverage performance have received inflated rewards, while they themselves were subject to a deflated evaluation (Hartmann and Slapničar 2012b). This awareness is likely to decrease the feeling of relatedness among the subordinates. Moreover, the feeling of autonomy might suffer further if above-average performers find that an increase in effort is even likely to increase the discrepancy between the actual effort and their evaluation. Against this background, we state the following hypothesis:

\section{H4: Peer information reinforces the effect of centrality bias on autonomous motivation.}

The provision of peer information may also impact the relationship between centrality bias and procedural fairness perceptions. While the referent cognitions theory introduced in Sect. 2.4 predicts that fairness perceptions are based on a comparison of the actual performance evaluation outcome and a potential one, equity theory assumes that fairness perceptions are contingent on a comparison of an individual's own "return on effort" and the returns received by his peers (Adams 1965). According to equity theory, individuals expect to receive an "appropriate rate of return", which is the ratio of the benefits an individual receives (i.e., outcomes) and the contributions an individual makes (i.e., input) (Greenberg et al. 2007). Equity theory further assumes that an individual compares his own rate of return with those of his peers. In this context, equity is obtained if the rates of return (i.e., the output-input ratios) are equal among the focal individual and his peers (Adams 1965). This equity considerably shapes the fairness perception of an evaluation process.

Centrality bias leads to inequity, given that the undervaluation of above-average performers and the overvaluation of below-average performers imply different rates of returns. Therefore, we assume that above-average performers who have access to peer information will consider their reward unfair. Due to the perceived unfairness, an undervalued individual is expected to restore equity by decreasing his input (Carrell and Dittrich 1978; Franco-Santos et al. 2012). Thus, we expect that the negative relationship between centrality bias and procedural fairness perceptions becomes stronger. In a similar vein, we expect that below-average performers consider the inequity resulting from centrality bias unfair as well if they are inequity averse, even though they are currently beneficiaries of this bias. Formally stated, these expectations lead to the following hypothesis:

H5: Peer information reinforces the effect of centrality bias on procedural fairness perceptions. 


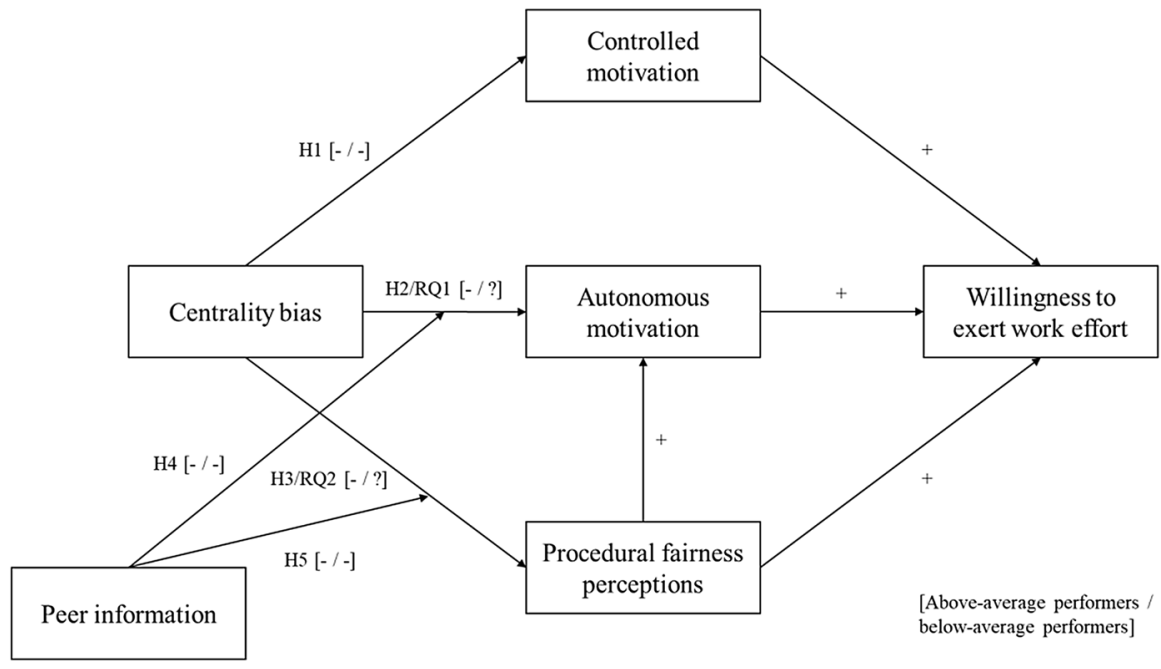

Fig. 1 Summary of conceptual model

\subsection{Summary}

Figure 1 summarizes our hypotheses and research questions. For above-average performers, we predict that controlled and autonomous motivation as well as procedural fairness perceptions negatively mediate the relationship between centrality bias and the willingness to exert work effort. Therefore, we expect a negative overall effect of centrality bias on the willingness to exert work effort. For below-average performers, the prediction of an overall effect is less straightforward as the partial effects of controlled and autonomous motivation as well as procedural fairness perceptions appear ambiguous. Therefore, it is unclear ex ante whether the overall effect is a positive or negative association between centrality bias and the willingness to exert work effort or whether there is no association at all.

\section{Method}

\subsection{Experimental design}

We investigated our hypotheses and research questions by using a vignette experiment with a $2 \times 2 \times 2 \times 2$ between-subjects design. Thus, the experiment relies on 16 different vignettes. A vignette is "a short, carefully constructed description of a person, object, or situation, representing a systematic combination of characteristics" (Atzmüller and Steiner 2010, p. 128). It consists of a series of text modules, for which the experimenters construct different attributes. In line with Kunz (2015), the vignettes used in our study rely on a binary set of attributes for each of the four varying text modules. As other types of experiments, vignette experiments reveal 
a high degree of internal validity, as the experimenters have control over the variables (Birnberg et al. 1990). However, vignette experiments do not capture the participants' actual behaviour, but their behavioural intentions (Kunz and Linder 2012). Therefore, vignette experiments appear particularly applicable to studies that intend to assess unobservable measures such as intentions and attitudes (Aguinis and Bradley 2014; Kunz and Linder 2012). Hence, the vignettes are complemented by a questionnaire that captures these intentions and attitudes. In our case, the questionnaire primarily refers to the participants' motivation and fairness perception as well as their willingness to exert additional work effort against the background of the described situation.

Similarly as in Kunz (2015) and Kunz and Linder (2012), the participants read the description of a hypothetical work situation and were asked to decide about the degree of additional work effort she or he is willing to exert. The work situation stated that the participant worked as a consultant who was engaged in a management accounting project along with the project manager and four further consultants with a similar working experience as the participant was assumed to have (see the Appendix for the full text). The vignette contained some information about the work climate to help participants to relate to the situation. The participants were told that they receive a bonus payment to compensate them for their prior work effort, given that the first of four project milestones was just completed. The text declared the bonus determination a responsibility of the project manager. It went on by stating that the executive board of the consulting firm recommended to the project manager to refer to the individual overtimes for the bonus assessment; however, eventually the project manager was authorized to decide freely and entirely on his own on the rewards. For this reason, our setting reflects a situation, in which the superior has the discretion to adjust an objective measure (i.e., overtimes) based on his subjective assessment. Given that the experimental variables rely on newly developed specifications, we pre-tested and discussed the vignettes with several management accounting researchers as well as 24 graduate students who were not part of the final sample. Based on their feedback, we slightly adjusted the wording of individual text modules.

\subsection{Measures}

\subsubsection{Experimental variables}

Each vignette comprises two fixed text modules and four additional modules that represent the manipulated variables (see the Appendix for each version of the text modules). As we expect that the behavioural implications of centrality bias differ between below-average and above-average performers, the first variable refers to the participant's performance. We manipulated it by integrating a text cue either stating that the participant had worked more or less overtime than the project team average. For our analyses, we employed a dummy variable (PERFORMANCE) that captures the different scenarios: We coded below-average performers as 1 and above-average performers as 0 . The second variable refers to the presence or non-presence of centrality bias. Instead of disclosing any amounts, we manipulated it in presence 
Panel A: Conditions with centrality bias and without provision of peer information

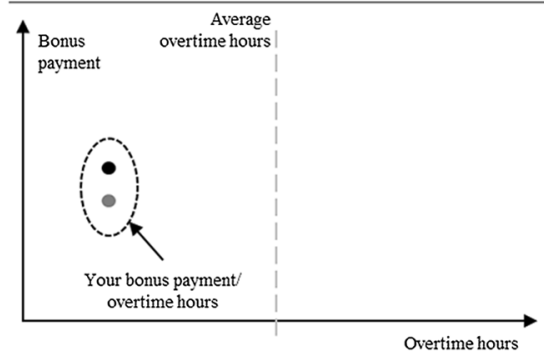

The black point represents the bonus payment you have received. The grey point represents the potential bonus payment that you would have received based on your overtime hours.

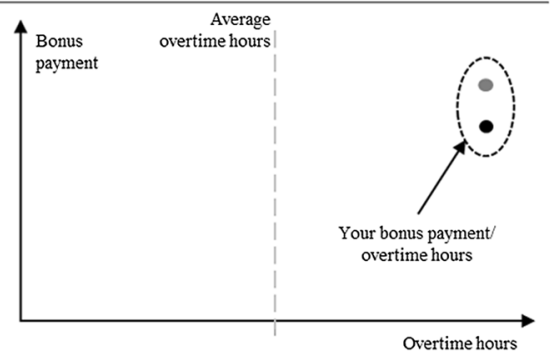

The black point represents the bonus payment you have received. The grey point represents the potential bonus payment that you would have received based on your overtime hours.

Panel B: Conditions with centrality bias and provision of peer information

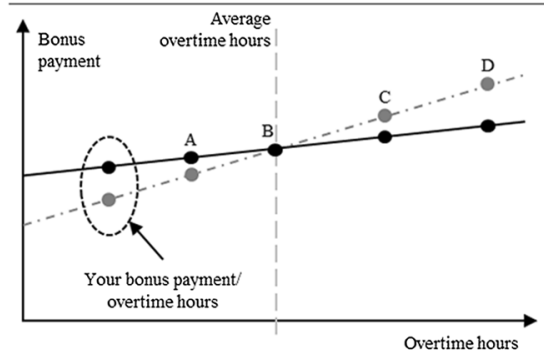

The points on the black line represent the bonus payments that you and your colleagues have received.

The points on the dotted grey line represent the potential bonus payments that you and your colleages would have received based on overtime hours.

Points A, B, C, and D represent the bonus payments/overtime hours of your colleagues.

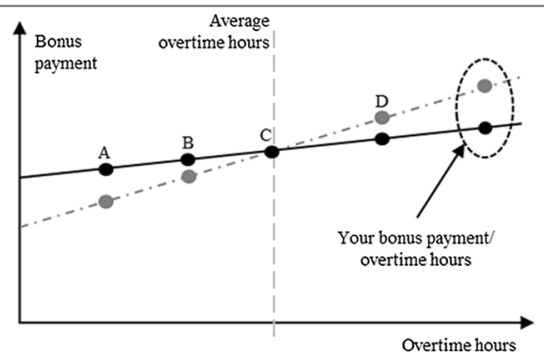

The points on the black line represent the bonus payments that you and your colleagues have received.

The points on the dotted grey line represent the potential bonus payments that you and your colleages would have received based on overtime hours.

Points A, B, C, and D represent the bonus payments/overtime hours of your colleagues.

\section{Panel C: Conditions without centrality bias and with provision of peer information}

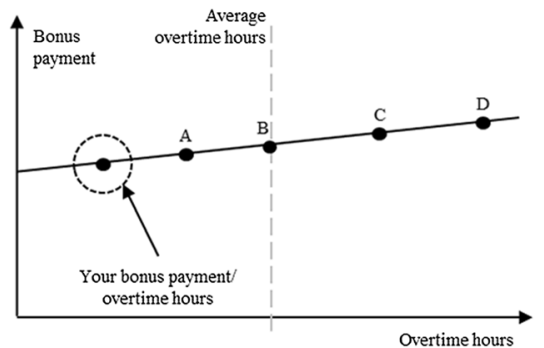

The points on the black line represent the bonus payments that you and your colleagues have received.

Points $\mathrm{A}, \mathrm{B}, \mathrm{C}$, and $\mathrm{D}$ represent the bonus payments/overtime hours of your colleagues.

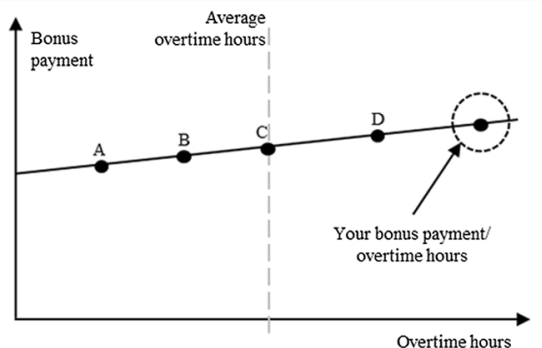

The points on the black line represent the bonus payments that you and your colleagues have received.

Points $A, B, C$, and $D$ represent the bonus payments/overtime hours of your colleagues.

Fig. 2 Graphic representation of bonus payments and overtime hours included in the vignettes 
Table 1 Statistics regarding work effort scale

\begin{tabular}{|c|c|c|}
\hline Item & Mean & SD \\
\hline \multicolumn{3}{|l|}{ Variable: OVERTIME } \\
\hline \multicolumn{3}{|c|}{$\begin{array}{l}\text { Question: Given the aforementioned context and the fact that you work currently } 39 \mathrm{~h} \text { per week on the } \\
\text { project: How will you behave? Please indicate the degree of agreement with the following statements }\end{array}$} \\
\hline I will spend an additional $5 \mathrm{~h}$ per week on the project. & 4.15 & 1.67 \\
\hline $\begin{array}{l}\text { I will continue working until I have finished a time-critical part of the project, although I } \\
\text { have already passed my normal daily working hours. }\end{array}$ & 4.88 & 1.44 \\
\hline I will work also during weekends to finish a time-critical part of the project. & 3.25 & 1.64 \\
\hline I will skip parts of my holidays to finish a time-critical part of the project. & 2.33 & 1.37 \\
\hline
\end{tabular}

Question and items taken from Kunz (2015). The scale ranged from 1 ("I do not agree at all") to 7 ("I fully agree")

of a centrality bias through one of the graphical representations shown in Panel A and B of Fig. 2. These figures reveal whether the monetary reward was inflated or deflated as compared to the one to which the participant was eligible based on his or her overtime. When no centrality bias was present, the vignette included a text cue stating that the participant had received a bonus equalling the one that he or she is entitled to according to his or her overtime hours. For the regression analyses, we employed a dummy variable $(B I A S)$ taking the value 1 in the presence of centrality bias and 0 otherwise.

The third variable captures the provision of peer performance and compensation information. If peer information was provided, a figure showed the proportion of the bonus received by the participant and the rewards which were received by his or her colleagues (Panels B and C in Fig. 2). For simplicity, we indicated a linear relationship between the overtime provided and the bonuses received. The provision of peer information (PEER) was coded 1 for the regression analyses and 0 otherwise. Eventually, we manipulated the overall work situation by describing either a relatively positive or a relatively negative work environment. For this reason, we drew on the text modules from Kunz (2015). The positive work situation (SITUATION) was coded 1 , the negative one $0 .{ }^{8}$ In contrast to the aforementioned explanatory variables, the work situation is a control variable to make the scenario more realistic and to avoid that the participants relate the scenario with a specific situation from their experience, which is outside of the experimenters' control (Kunz 2015).

\subsubsection{Dependent variable}

The participants' willingness to exert additional work effort serves as our main dependent variable. Since work effort cannot be directly observed in a vignette experiment, we relied on the multi-item 7-point Likert scale instrument used by Kunz (2015) and Kunz and Linder (2012) that measures a participant's willingness

\footnotetext{
8 In order to enrich the description of the working environment, we combined two text modules from Kunz (2015). A drawback of this merging is that the work climate implies a flavour of work autonomy.
} 
Table 2 Statistics regarding motivation scales

\begin{tabular}{|c|c|c|}
\hline Item & Mean & $\mathrm{SD}$ \\
\hline \multicolumn{3}{|l|}{$\begin{array}{l}\text { Panel A } \\
\text { Variable: CONT_MOT }\end{array}$} \\
\hline \multicolumn{3}{|c|}{$\begin{array}{l}\text { Question: Why do you invest the previously indicated additional working time? Please indicate the } \\
\text { degree of agreement with the following statements: I provide this level of additional working time... }\end{array}$} \\
\hline ... because I get paid for the project work. & 5.49 & 1.29 \\
\hline ... because the project work allows me in the long run to make a lot of money. & 5.24 & 1.36 \\
\hline ... because the project work affords me in the long run a certain standard of living. & 5.06 & 1.43 \\
\hline \multicolumn{3}{|l|}{$\begin{array}{l}\text { Panel B } \\
\text { Variable: AUT_MOT }\end{array}$} \\
\hline \multicolumn{3}{|c|}{$\begin{array}{l}\text { Question: Why do you invest the previously indicated additional working time? Please indicate the } \\
\text { degree of agreement with the following statements: I provide this level of additional working time... }\end{array}$} \\
\hline ... because I have fun doing the project work. & 4.60 & 1.46 \\
\hline ... because what I do in the project work is exciting. & 4.73 & 1.39 \\
\hline ... because the project work is interesting. & 4.84 & 1.31 \\
\hline ... because of the moments of pleasure that the project work brings me. & 3.97 & 1.42 \\
\hline ... because I personally consider it important to put efforts in the project work. & 4.75 & 1.44 \\
\hline ... because putting efforts in the project work aligns with my personal values. & 4.72 & 1.49 \\
\hline ... because putting efforts in the project work has personal significance to me. & 4.13 & 1.50 \\
\hline
\end{tabular}

Question and items taken from Gagné et al. (2015) and Kunz (2015). The scale ranged from 1 ("I do not agree at all") to 7 ("I fully agree")

to exert additional work effort. Following the description of the work situation, the questionnaire asked the participants to state their degree of agreement $(1=\mathrm{I}$ do not agree at all; $7=$ I fully agree) with the four statements shown in Table 1 . Since these statements refer to the participants' willingness to work overtime, we labelled the variable OVERTIME. We applied a principal component analysis with varimax rotation, which suggested that the four items represent one underlying factor (eigenvalue 2.20), explaining $55.1 \%$ of the total variance with all factors loading above 0.68 . A KMO test revealed a value of 0.68 , a Bartlett test indicated significance below the 0.01 level. Cronbach's alpha of the measurement instrument was 0.73 . For our analyses, we used the sum scores of the four items.

\subsubsection{Motivation types}

Our measurement of autonomous and controlled motivation relies on the motivation at work scale by Gagné et al. (2015, 2010), which has been used in previous vignette experiments (Kunz 2015; Kunz and Linder 2012; Linder 2016). The wording of single items was slightly modified to account for our specific experimental context. The participants were asked why they are willing to exert the specified level of additional work effort. For this reason, the participants had to indicate their level of agreement with the ten items reported in Table 2. The three items shown in Panel A of Table 2 measure controlled motivation (variable CONT_MOT) and were taken from Kunz (2015). The measures for autonomous motivation (variable $A U T \_M O T$ ) reported in 
Table 3 Statistics regarding procedural fairness scale

\begin{tabular}{lll}
\hline Item & Mean & SD \\
\hline Variable: FAIRNESS & \\
Instruction: Please indicate the degree of agreement with the following statements & 4.10 & 1.66 \\
I trust that the decision on my bonus is fair. & 3.66 & 1.55 \\
I have full confidence in the procedure with which my superior has determined the bonus. & 4.10 & 1.68 \\
I trust that the criteria that were used to determine my bonus are fair. & 3.85 & 1.77 \\
I am very satisfied with the way in which my bonus was determine.
\end{tabular}

Question and items taken from Voußem et al. (2016). The scale ranged from 1 ("I do not agree at all") to 7 ("I fully agree")

Panel B of Table 2 reflect that both enjoyment as well as alignment with personal values may be drivers of the autonomous motivation to exert work effort. The measures reported in both panels were taken from Gagné et al. (2015) and Kunz (2015). A principal component analysis with varimax rotation indicated that the items represent two underlying factors with eigenvalues of 3.82 (AUT_MOT) and 2.26 (CONT_MOT) explaining 38.2 and $22.3 \%$ of total variance. Factor loadings were at least 0.65 and cross-loadings were below 0.15. A KMO test indicated a value of 0.79, a Bartlett test showed significance below the 0.01 level. Cronbach's alpha of the measurement instruments were 0.86 (AUT_MOT) and 0.81 (CONT_MOT). For the regression analyses, we used the sum scores of the respective items.

\subsubsection{Procedural fairness perceptions}

Given that we are interested in the perceived fairness (FAIRNESS) of the procedure used to determine the bonus, our specification of fairness perceptions relies on items used in the prior literature to measure procedural fairness. ${ }^{9}$ More precisely, we measure FAIRNESS based on the items used by Voußem et al. (2016), which we slightly adjusted to account for our experimental context. As with the different types of motivation, the participants were asked to indicate their level of agreement with the four items reported in Table 3. A principal component analysis with varimax rotation suggests that the four items represent one underlying factor (eigenvalue 3.14 ), explaining $78.4 \%$ of the total variance with all factors loading above 0.85 . A KMO test revealed a value of 0.85 , a Bartlett test indicated significance below the 0.01 level. Cronbach's alpha of the measurement instrument was 0.91 . We used the sum score of these items for our regression analyses.

\subsubsection{Control variables}

To test the ecological validity of the vignettes, we included three questions on their comprehensibility, traceability and closeness to reality from Kunz (2015). The participants were asked to state their degree of agreement based on a 7-point

\footnotetext{
9 As outlined in Sect. 2.4, we thus exclude perceptions of distributive fairness (Burney et al. 2009).
} 
Likert scale. Comprehensibility was measured based on the item "How well did you understand the presented work situation?" (COMPREHEN; $1=$ very poorly; $7=$ very well), while the item "How easily could you put yourself into the presented work situation?" measured the traceability of the vignettes $(T R A C E ; 1=$ very difficult; 7 = very easy). Eventually, the item "How would you rate the closeness of the work situation described above to real-life situations?" measured the perceived closeness to reality (REALITY; $1=$ very unrealistic; $7=$ very realistic). Furthermore, we controlled for the participants' age ( $A G E$; in years) and gender. For the latter, we introduced the variable FEMALE which equals 1 in the case of female participants and 0 otherwise. We also considered that the attractiveness of consultancy work may have an impact on the willingness to exert work effort in the given situation. For this reason, we added an item asking "How attractive is a career as a consultant for you (irrespective of the described situation)?" (ATTRACTIVE; $1=$ very unattractive; $7=$ very attractive). Eventually, we relied on the dummy variable EXPOSURE to distinguish between graduate and undergraduate students used because of the rationale outlined in Sect. 3.3. All these items entered our analyses as control variables.

\subsection{Data collection}

The participants in our experiment were 325 undergraduate students and 126 graduate students in business administration enrolled at a German university. ${ }^{10} \mathrm{We}$ excluded the questionnaires from 21 undergraduate students and 5 graduate students as they failed the manipulation check. Therefore, we used 425 responses in total for our analyses. t-tests on all variables (except for AGE) did not reveal any significant differences. ${ }^{11}$ Therefore, we considered both samples simultaneously in our analyses. In line with our between-subject design, each participant received one randomly assigned vignette with the questionnaire. We abstained from the provision of detailed information on the study's objectives to ensure that the participants replied to the questionnaire unbiased. Therefore, the students were only told that the study contributes to a deeper understanding of the effects of performance measurement systems. For minimising the threat of social desirable responses, full anonymity and confidentiality were guaranteed (Kunz 2015).

Due to the reliance on students, our participants have restricted working experience and thus may confine the external validity of our findings. However, in line with Kunz (2015) we argue that the involvement of students has at least two major advantages. On the one hand, students are used to getting evaluated during their university and school education. In many cases, such evaluation relies on subjective assessments. For this reason, they have developed some understanding for the situation described in the vignettes. On the other hand, they are unlikely to have yet a

\footnotetext{
${ }^{10}$ While the material was provided to the participants in German, this paper relies on a self-produced translation of the material.

11 We did not perform a test on EXPOSURE, given that being an undergraduate or graduate student is the separation criterion for this variable.
} 
notion of a generally accepted design of a performance measurement system or of a socially desired reaction to it. Therefore, past experiences with performance measurement systems are unlikely to confound our findings. Nevertheless, the graduate students participating in our study may have attended lectures on subjective performance measurement. If they are familiar with performance evaluation biases, issues regarding socially desirable answers might occur. This concern is put into perspective as the curriculum of the master studies at the university at which the experiment took place does not cover issues related to subjective performance evaluation. However, as we cannot rule out entirely that the graduate students have higher exposure to performance measurement topics, we added the control variable EXPOSURE as outlined above.

Despite these limitations, we argue that the students' familiarity with evaluations in general is likely to increase the understandability and traceability of the presented situation. At the same time, we argue that their limited experience with performance measurement systems contributes to the internal validity of our study as it appears less of a concern that past experiences interact with the participants' attitude revealed in the experiment.

\section{Findings}

\subsection{Manipulation checks and descriptive statistics}

We included several items in the questionnaire to check the effectiveness of our manipulations. For all manipulation check items, we asked the participants to state their level of agreement on a 7-point Likert scale $(1=\mathrm{I}$ do not agree at all; $7=\mathrm{I}$ fully agree). For the examination of the performance manipulation, we used the item "My overtime hours are above the project team average.". The mean score on this item is significantly $(\mathrm{t}=28.68, \mathrm{p}<0.001)$ higher in the above-average performance condition (mean $=5.85, \mathrm{SD}=1.62)$ than in the below-average performance condition $($ mean $=1.85, \mathrm{SD}=1.24)$. To test the manipulation of centrality bias, we relied on the item "The bonus that I have received corresponds with the bonus to which I am eligible based on my overtime hours.". The mean score on this item is 2.21 $(\mathrm{SD}=1.45)$ in the bias condition and $5.32(\mathrm{SD}=1.59)$ in the non-bias condition. We find that the difference between the scores is highly significant $(\mathrm{t}=21.04, \mathrm{p}<0.001)$. For the test on the disclosure of peer information, we included the item "I know the ratio of my bonus to those of my colleagues.". The mean score on this item is higher for the condition, in which peer information is disclosed (mean $=5.88, \mathrm{SD}=1.34$ ), as compared to the situation in which such information is not available (mean $=2.20$, $\mathrm{SD}=1.81)$. This difference is significant $(\mathrm{t}=23.57, \mathrm{p}<0.001)$. As our manipulation of work climate refers to the participant's self-determination in the work process as well as to the cooperation behaviour in the team, we included two items to test the effectiveness of our work climate manipulation. The item reflecting the first dimension states "The project work enables me to perform tasks self-determinately.". The mean score for the condition with a good work climate is $5.80(\mathrm{SD}=0.92)$ as compared to a mean of $2.58(\mathrm{SD}=1.59)$ for the condition with poor work climate. The 
Table 4 Descriptive statistics on the willingness to exert work effort (OVERTIME)

\begin{tabular}{|c|c|c|c|c|c|c|c|c|c|c|}
\hline & \multicolumn{3}{|c|}{ Centrality bias } & \multicolumn{3}{|c|}{ No centrality bias } & \multirow[t]{2}{*}{$\mathrm{t}^{\mathrm{a}}$} & \multicolumn{3}{|c|}{ Overall } \\
\hline & $\mathrm{n}$ & Mean & SD & $\mathrm{n}$ & Mean & $\mathrm{SD}$ & & $\mathrm{n}$ & Mean & $\mathrm{SD}$ \\
\hline \multicolumn{11}{|c|}{ Panel A: full sample } \\
\hline \multicolumn{11}{|l|}{ Peer information } \\
\hline Disclosed & 109 & 13.84 & 4.89 & 115 & 15.37 & 4.07 & $-2.52 * * *$ & 224 & 14.63 & 4.54 \\
\hline Not disclosed & 105 & 13.59 & 4.53 & 96 & 15.67 & 4.38 & $-3.30 * * *$ & 201 & 14.58 & 4.57 \\
\hline \multicolumn{11}{|c|}{ Panel B: above-average performer conditions } \\
\hline \multicolumn{11}{|l|}{ Peer information } \\
\hline Disclosed & 55 & 12.51 & 4.52 & 54 & 16.04 & 4.38 & $-4.14 * * *$ & 109 & 14.26 & 4.77 \\
\hline Not disclosed & 54 & 12.46 & 4.50 & 49 & 15.41 & 4.27 & $-3.40 * * *$ & 103 & 13.86 & 4.61 \\
\hline \multicolumn{11}{|c|}{ Panel C: below-average performer conditions } \\
\hline \multicolumn{11}{|l|}{ Peer information } \\
\hline Disclosed & 54 & 15.20 & 4.92 & 61 & 14.77 & 3.71 & 0.53 & 115 & 14.97 & 4.31 \\
\hline Not disclosed & 51 & 14.78 & 4.29 & 47 & 15.94 & 4.52 & -1.30 & 98 & 15.34 & 4.41 \\
\hline
\end{tabular}

difference is significant $(t=25.52, \mathrm{p}<0.001)$. The item on cooperation states "The project work is characterized by a cooperative mode of operation.". We find that the mean score is significantly $(\mathrm{t}=22.96, \mathrm{p}<0.001)$ higher for the condition of good work climate (mean $=5.91, \mathrm{SD}=0.95)$ as compared to the condition of poor work climate (mean $=2.97, \mathrm{SD}=1.61)$. In light of these findings, we conclude that all of our manipulations were effective.

Table 4 reports descriptive statistics on our main dependent variable- the participants' willingness to exert additional work effort (OVERTIME). Panel A provides the numbers of participants, mean scores and standard deviations for the willingness to exert work effort for the conditions with and without centrality bias as well as with and without disclosure of peer information for the full sample. We find that the participants that are subject to centrality bias are less willing to exert work effort as compared to the participants that receive an unbiased reward. This tendency holds true, irrespective of whether peer information is disclosed. Two-sample t-tests for the difference between the means of OVERTIME in the conditions with and without centrality bias suggest that the difference is significant at the 0.01 level, both in presence as well as in absence of peer information.

Further insights are provided when we separate the participants in the aboveaverage performance condition (Panel B) from those of the below-average performance condition (Panel C). We find the highest mean score for above-average performers in the cell without centrality bias but with disclosure of peer information (mean $=16.04, \mathrm{SD}=4.38$ ). The mean score is the lowest for above-average performers that are subject to bias and do not have peer information (mean $=12.46$, $\mathrm{SD}=4.50$ ). For above-average performers, $t$-tests indicate that the mean differences between the conditions with and without centrality bias are significant at the 0.01 
Table 5 OLS regression results on the direct effect of centrality bias on the willingness to exert work effort

\begin{tabular}{|c|c|c|c|c|c|c|}
\hline \multirow[t]{3}{*}{ Variable name } & \multicolumn{6}{|c|}{ Dependent variable: OVERTIME } \\
\hline & \multicolumn{2}{|l|}{ Panel A: overall } & \multicolumn{2}{|l|}{ Panel B: above average } & \multicolumn{2}{|l|}{ Panel C: below average } \\
\hline & Coefficient estimate & SE & Coefficient estimate & SE & Coefficient estimate & SE \\
\hline Constant & $10.528 * * *$ & 2.209 & $17.345 * * *$ & 3.463 & 4.845 & 2.956 \\
\hline BIAS & $-1.853 * * *$ & 0.424 & $-3.007 * * *$ & 0.602 & -0.662 & 0.592 \\
\hline PEER & 0.009 & 0.422 & 0.470 & 0.593 & -0.576 & 0.578 \\
\hline SITUATION & 0.620 & 0.429 & 0.542 & 0.605 & $1.018 *$ & 0.598 \\
\hline COMPREHEN & 0.008 & 0.249 & -0.167 & 0.339 & 0.200 & 0.360 \\
\hline TRACE & $0.389 *$ & 0.206 & 0.184 & 0.296 & $0.596^{* *}$ & 0.281 \\
\hline REALITY & 0.120 & 0.176 & 0.162 & 0.248 & -0.001 & 0.247 \\
\hline FEMALE & 0.582 & 0.428 & 0.930 & 0.610 & 0.284 & 0.582 \\
\hline AGE & -0.044 & 0.077 & $-0.280 * *$ & 0.138 & $0.170^{*}$ & 0.102 \\
\hline ATTRACTIVE & $0.546^{* * *}$ & 0.127 & $0.561 * * *$ & 0.171 & 0.385 & 0.189 \\
\hline EXPOSURE & 0.614 & 0.493 & 0.538 & 0.894 & $1.504 * *$ & 0.640 \\
\hline $\mathrm{R}^{2}$ & 0.125 & & 0.211 & & 0.093 & \\
\hline $\mathrm{n}$ & 425 & & 212 & & 213 & \\
\hline
\end{tabular}

Coefficients of binary variables indicate the effect when the binary variable of interest equals 1

$*$, **, ***Significant at the $0.1,0.05,0.01$ level, respectively

level. For the below-average performers, the difference between the mean scores in the conditions with and without centrality bias is considerably lower. Correspondingly, the t-tests find that the difference in means is not significant. Nevertheless, we observe the tendency that participants in the below-average condition are on average willing to exert slightly more effort in presence of centrality bias as compared to the non-bias condition, when peer information is disclosed. The same holds true reciprocally for the conditions, in which no peer information is given.

\subsection{The overall effect of centrality bias on the willingness to exert work effort}

In the following, we first estimate the overall effect of centrality bias on the willingness to exert work effort, before we shed light on the psychological mechanisms that may explain this relationship. Based on the insights from the social psychology literature, we suggested in Sect. 2.6 a negative overall effect of centrality bias on the willingness to exert work effort for above-average performers and made no prediction for below-average performers since centrality bias may induce opposing psychological mechanisms. In order to test these propositions, we regress OVERTIME on BIAS and the control variables using an OLS regression. We perform this analysis for the full sample as well as separately for the above-average as well as belowaverage performers to detect differences between these conditions. Table 5 (Panel A) reports the regression results for the full sample and shows that the coefficient 
for BIAS is negative and significant at the 0.01 level. The findings reported in Panel $\mathrm{B}$ and $\mathrm{C}$ suggest that this relationship is considerably driven by the above-average performers. Panel B, which reports the findings for the sub-sample of above-average performers, shows that the significant and negative coefficient for BIAS is considerably higher in this condition. This finding supports our expectation that centrality bias is negatively associated with the willingness of above-average performers to exert work effort. In contrast, the coefficient of BIAS is not significant in the subsample of below-average performers as shown in Panel C. This finding suggests that centrality bias does not significantly affect the willingness to exert work effort among below-average performers. This result is in line with our argument that there might be no association because of the opposing mechanisms discussed in Sect. 2.

\subsection{The mediating effects of motivation and fairness perceptions}

Our theoretical considerations suggest that controlled motivation, autonomous motivation and procedural fairness perceptions may mediate the relationship between centrality bias and the willingness to exert work effort. For this reason, they may explain the reported overall effects. Mediation models include two causal paths: the direct relationship between the independent variable (BIAS) and the dependent variable (OVERTIME) as well as an indirect relationship including one path from BIAS to the mediator (AUT_COT, CON_MOT and FAIRNESS, respectively) and one from the mediator to OVERTIME. Correspondingly, Baron and Kenny (1986) suggest to estimate a series of regression models to test for mediation. In line with the aforementioned causal paths, OVERTIME is first regressed on BIAS. In a second step, the mediator is regressed on BIAS. Eventually, OVERTIME is regressed on BIAS and the mediator. To establish mediation, BIAS must be significantly related to OVERTIME in the first equation and to the mediator in the second equation. Eventually, the mediator must be significantly related to OVERTIME in the third equation. A partial mediation requires that the relationship between BIAS and OVERTIME is weaker in the third equation than in the first one. In other words, if there is a mediation, the direct relationship between BIAS and OVERTIME is weaker when we control for the indirect effect of BIAS on OVERTIME through the mediator. In case of a full mediation, there is no significant relationship between BIAS and OVERTIME in the third equation (Baron and Kenny 1986).

In order to test the mediating effects of autonomous motivation (AUT_MOT), controlled motivation (CON_MOT) and procedural fairness perceptions (FAIRNESS), we used the PROCESS macro for SPSS introduced by Hayes (2013). PROCESS relies on a series of OLS regressions to estimate the path coefficients in a mediation model as suggested by the outlined causal steps approach by Baron and Kenny (1986). It also generates bootstrap confidence intervals for the total and indirect effects (Hayes et al. 2017). The findings from the first equation (the regression of OVERTIME on BIAS) can be taken from Table 5. Rows 1-3 of Table 6 report the findings from the second equations, in which the respective mediator is regressed on BIAS, whereas Row 4 refers to the third equation, in which OVERTIME is regressed 


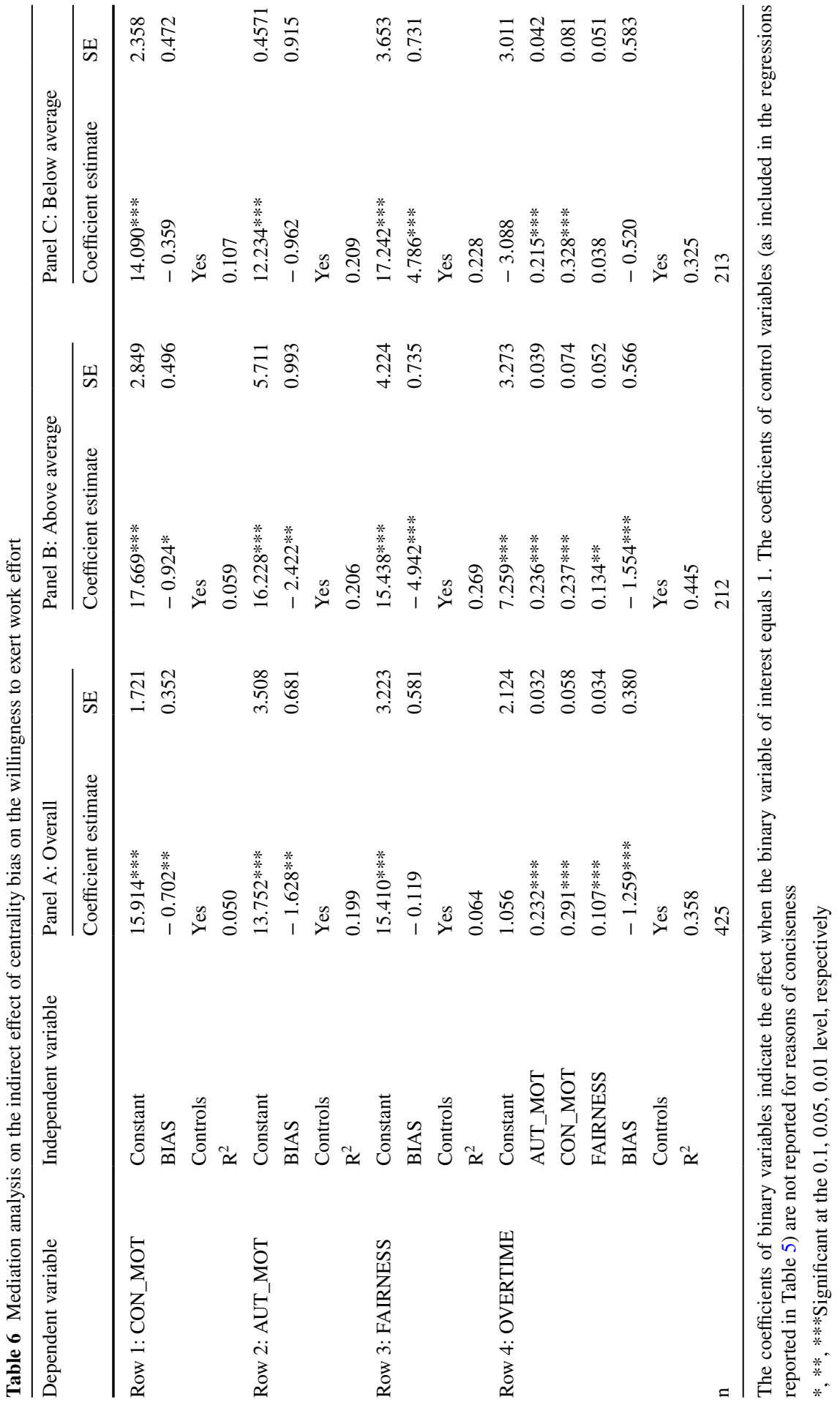


on the mediators and BIAS. We conducted these analyses for the full sample as well as separately for above-average and below-average performers.

As shown in Panel A, we find that BIAS is negatively and significantly associated with AUT_MOT and CON_MOT respectively (Rows 1 and 2). These findings suggest that both types of motivation decrease in presence of BIAS. Row 4 reports positive and significant coefficients for both types of motivation on the willingness to exert work effort. Moreover, we find that the coefficient for BIAS is considerably smaller when we control for the indirect effect through the mediators as compared to the regression that estimates the direct effect of BIAS only (see Table 5). These findings suggest that the relationship between BIAS and OVERTIME is partially mediated by autonomous as well as controlled motivation. In contrast, we do not find that BIAS is significantly associated with FAIRNESS (Row 3), suggesting that FAIRNESS does not mediate the relationship between BIAS and OVERTIME.

However, these findings are put into perspective when we illuminate aboveaverage and below-average performers separately. According to Panel B of Table 6, BIAS is significantly and negatively related to AUT_MOT and CON_MOT for above-average performers (Rows 1 and 2). We also detect positive and significant coefficients for AUT_MOT and CON_MOT on OVERTIME. These findings are in line with H1, which refers to the mediating role of CON_MOT. Moreover, we find support for H2, which predicts that AUT_MOT negatively mediates the relationship between BIAS and OVERTIME for above-average performers. In contrast, there is no significant relationship between BIAS and AUT_MOT as well as between BIAS and CON_MOT for below-average performers (Panel C, Rows 1 and 2). BIAS is negatively associated with the two types of motivation for below-average performers. However, this relation is weaker than for above-average performers and not significant. Therefore, $\mathrm{H} 1$ is only partially, i.e. for above-average performers, supported. However, the non-significant relationship between BIAS and AUT_MOT is in line with our reasoning related to RQ1 suggesting that the opposing effects of centrality bias on the psychological needs which determine autonomous motivation may result in a non-significant relationship between BIAS and AUT_MOT.

Row 3 of Panels B and C reveals some noteworthy findings regarding the mediating role of FAIRNESS. Whereas we do not find a significant relationship between BIAS and FAIRNESS for the full sample, we find that BIAS is negatively and significantly associated with FAIRNESS for above-average performers. This finding supports H3. Row 3 of Panel C implies a response to RQ2 as we find that for belowaverage performers, BIAS is highly significantly and positively related to FAIRNESS. Interestingly, we find that FAIRNESS is in turn positively and significantly associated with OVERTIME for above-average performers (Row 4 of Panel B). For below-average performers, however, this relationship is not significant (Row 4 of Panel C). These findings indicate that FAIRNESS is a partial mediator for aboveaverage performers only. For below-average performers, our findings suggest that they perceive their inflated reward as fair. Yet, this fairness perception does not seem to "translate" into a higher willingness to exert work effort.

While this analysis assumes a direct relationship between procedural fairness perceptions and the willingness to exert work effort, we argued in Sect. 2.4 that procedural fairness perceptions may be an antecedent to autonomous motivation, implying 


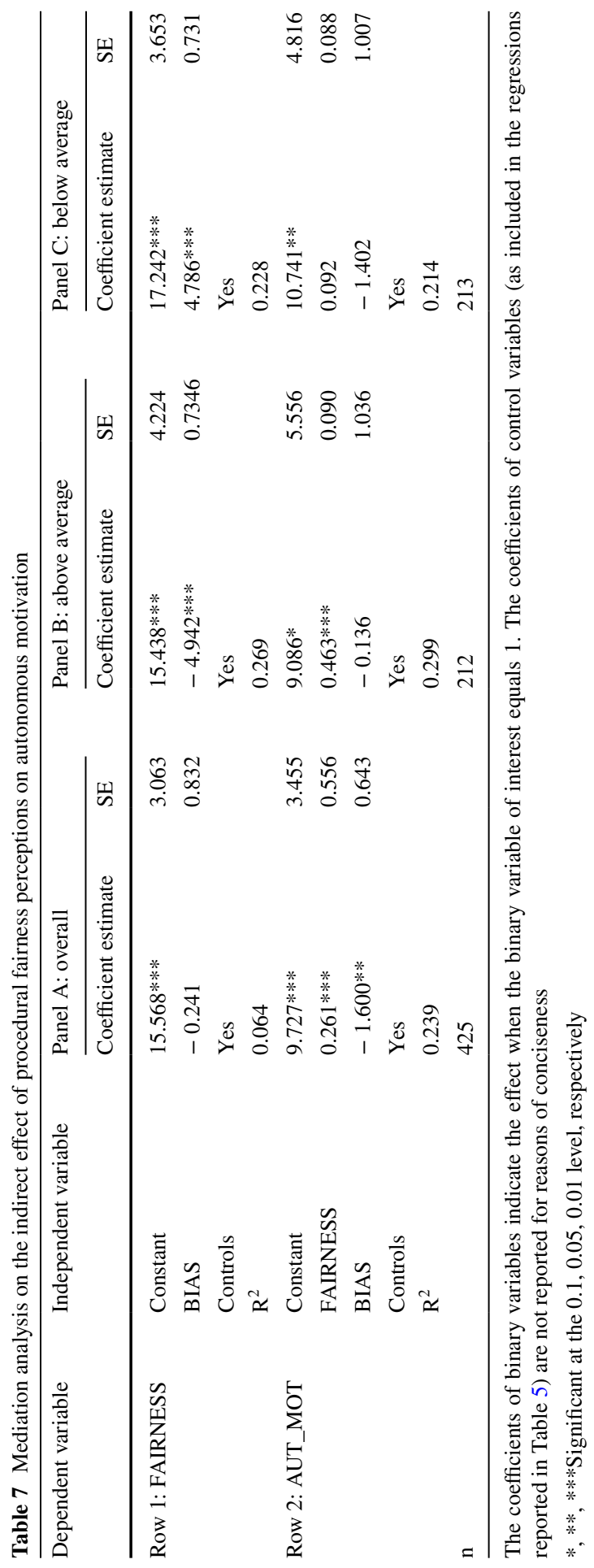


an indirect effect of FAIRNESS on OVERTIME mediated by AUT_MOT. In order to explore this possibility, we conducted an additional mediation analysis with BIAS as the independent variable, AUT_MOT as the dependent variable and FAIRNESS as the mediator. The corresponding results are reported in Table 7. The findings from the regression of AUT_MOT on BIAS can be taken from Table 6 (Row 2). Therefore, Row 1 of Table 7 refers to the regression of FAIRNESS on BIAS [second step according to the aforementioned procedure by Baron and Kenny (1986)], whereas Row 2 reports the findings from the regression of AUT_MOT on BIAS and FAIRNESS (third step of the mediation analysis). The findings shown in Panel B, Row 2 suggest that for above-average performers, the relationship between BIAS and AUT_MOT is fully mediated by FAIRNESS, given that the effect of BIAS on AUT_MOT is no longer significant when FAIRNESS as the mediator is included. We do not observe a similar effect for below-average performers. Instead, the findings reported in Panel $\mathrm{C}$ reemphasize that BIAS is positively related to FAIRNESS which is positively, but not significantly related to AUT_MOT.

\subsection{The moderating effects of peer information}

H4 and H5 predict that the associations of bias with autonomous motivation and with procedural fairness perceptions are moderated by the disclosure of peer information. These hypotheses thus suggest a two-way interaction between BIAS and PEER. To test these interactions, we constructed two models that were subject to an OLS regression. The first one includes AUT_MOT as the dependent variable, whereas FAIRNESS is the dependent variable of the second model. In both cases, BIAS, PEER and the interaction term BIASxPEER are the primary variables of interests.

Table 8 (Row 1) reports the findings with regard to autonomous motivation. The positive and significant coefficient for the two-way interaction of BIAS and PEER shown in Panel A suggests that the negative relationship between BIAS and AUT_ MOT is weaker when peer information is available. While our separate analyses for above-average performers (Panel B) and below-average performers (Panel C) reveal the same signs, we find that these coefficients are not significant. In other words, the negative relationship between BIAS and AUT_MOT tends to be weaker in presence of peer information, yet this effect is not significant. Therefore, we do not find support for H4, and conclude that the effect of BIAS on AUT_MOT does not differ significantly, depending on whether peer information is available or not.

The regression results with regard to FAIRNESS are reported in Row 2 of Table 8. The two-way interaction of BIAS and PEER is not significantly related to FAIRNESS for the full sample (Panel A). The same conclusion holds for the separate analysis of above-average (Panel B) and below-average performers (Panel C). The coefficient for the interaction term of BIAS and PEER is positive for aboveaverage performers. This finding suggests that the negative relationship between BIAS and FAIRNESS tends to be weaker when peer information is available. However, this finding is not significant. With regard to below-average performers, we find that the coefficient of BIASxPEER is negative. It indicates that the positive 


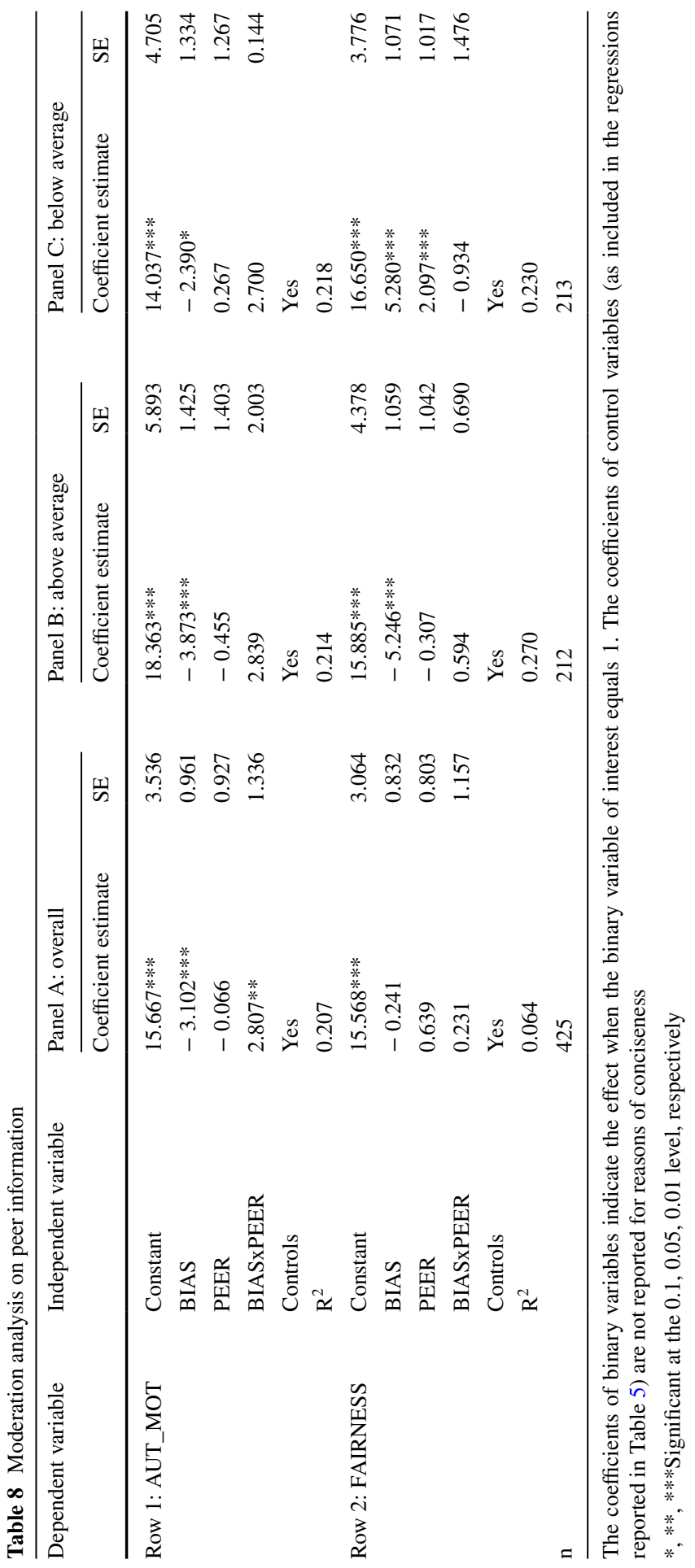




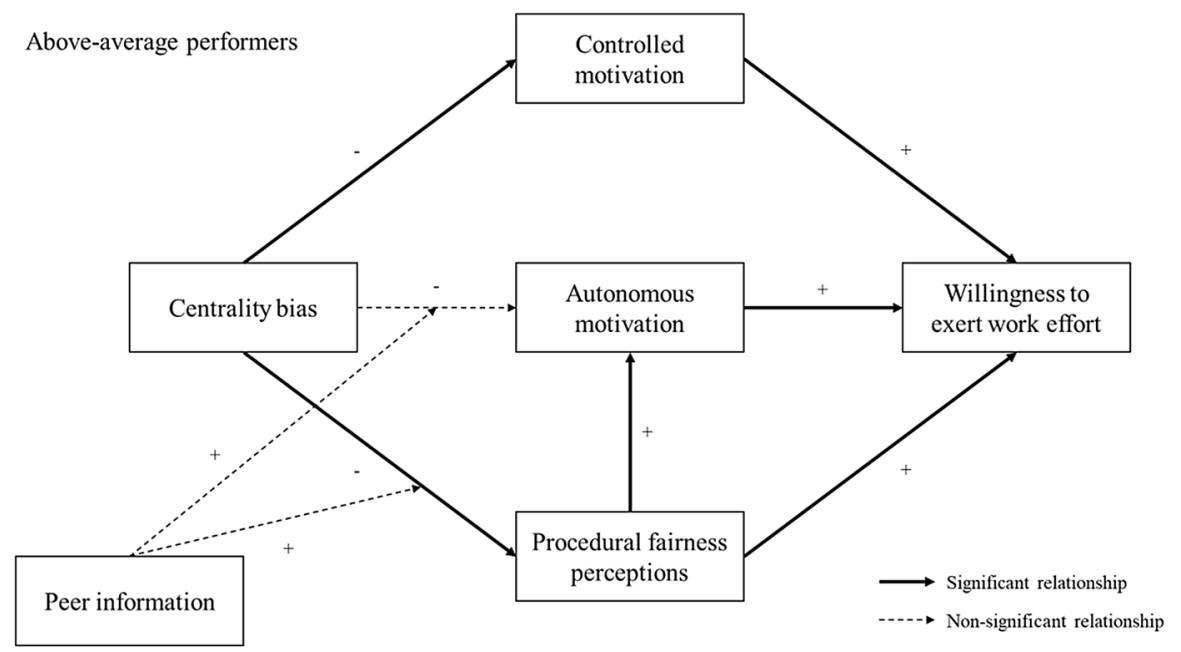

Fig. 3 Summary of findings for above-average performers

relationship between BIAS and FAIRNESS is weaker when peer information is disclosed, yet this effect is not significant. Taken together, we find no support for H5.

This analysis treats AUT_MOT and FAIRNESS as separate dependent variables. Since we found that the relationship between BIAS and AUT_MOT is fully mediated by FAIRNESS for above-average performers (see Table 7), we complement this analysis by a moderated mediation analysis including BIAS as the independent variable, FAIRNESS as the mediator, AUT_MOT as the dependent variable and PEER as the moderator. These untabulated findings do not change qualitatively with the exception that the direct relationship between BIAS and AUT_MOT is for the above-average performers no longer significant since it is mediated by FAIRNESS. Therefore, the previously outlined conclusions remain unaffected.

\section{Discussion}

Given that firms frequently rely on performance measurement systems which incorporate subjectivity, a thorough understanding of the emergence and effects of bias arising out of subjective performance evaluations appears important. Our study contributes to corresponding research endeavours by focusing on the psychological mechanisms activated by centrality bias. Our main argument is that bias is likely to trigger several psychological mechanisms, comprising controlled and autonomous motivation as well as procedural fairness perceptions. The distinction of controlled and autonomous motivation as well as the consideration of fairness perceptions enable us to develop a more sophisticated understanding of the effects of centrality bias on the willingness to exert work effort. A closer examination of these psychological mechanisms appears particularly interesting for below-average performers who benefit from centrality bias as they are overvalued. Based on insights from the social 
psychology literature, we discussed potentially opposing effects of centrality bias for this group, resulting in an ambiguous net effect. For above-average performers, we expected that controlled and autonomous motivation as well as procedural fairness perceptions negatively mediate the relationship between centrality bias and the willingness to exert work effort. We tested our hypotheses and answered our research questions based on data collected during a vignette experiment.

In line with our expectations, we find that centrality bias asymmetrically affects above-average and below-average performers. Figure 3 summarizes our findings for above-average performers, which are virtually in line with our hypotheses. The results suggest that the negative relationship between bias and performance improvements found in prior research (Ahn et al. 2010; Berger et al. 2013; Bol 2011; Engellandt and Riphahn 2011) can be explained by multiple and simultaneously occurring psychological mechanisms. We find that controlled motivation negatively mediates the relationship between centrality bias and the willingness to exert work effort. This finding supports the idea that-due to the disruption of the linkage between performance and reward (Baker et al. 1988; Prendergast 1999) — a change in effort implies a disproportionally low change in evaluation and rewards in presence of bias. Therefore, it appears rational for externally motivated individuals to decrease their effort. Based on self-determination theory, we predicted that centrality bias is negatively associated with autonomous motivation as well, because it mitigates the satisfaction of three basic psychological needs. We find empirical evidence for this hypothesis which is, however, put into perspective when we include procedural fairness perceptions as an antecedent of autonomous motivation. Our findings indicate a highly significant negative relationship between centrality bias and procedural fairness perceptions. Moreover, we find that procedural fairness perceptions fully mediate the relationship between centrality bias and autonomous motivation.

Our interpretation of this finding relies on the referent cognitions theory and suggests that this negative relationship results from a comparison of the potential reward, which relies on an objective measure, with the subjectively adjusted reward. We argue that above-average performers are likely to consider the procedure for the determination of the potential reward based on the objective measure more valid, suggesting that the adjustment is considered unfair. From the perspectives of social comparison theory and equity theory, it appears surprising that the disclosure of peer information does not significantly moderate the associations of centrality bias with autonomous motivation and with procedural fairness perceptions. These findings suggest that the awareness of the "source" of the bias does not impact the psychological mechanisms triggered. With regard to autonomous motivation, a potential explanation is that the marginal effects of disclosing peer information on the feelings of relatedness and autonomy are negligible. Concerning procedural fairness, we suggest that fairness perceptions obviously depend more strongly on comparisons with the unadjusted objective measure than on comparisons with peers.

Our findings for below-average performers are summarized by Fig. 4. In contrast to the above-average performers, we do not detect a significant relationship between centrality bias and the willingness to exert work effort for this group. This finding is in line with the idea that centrality bias activates divergent psychological mechanisms, resulting in an ambiguous net effect. Our analysis suggests that centrality 


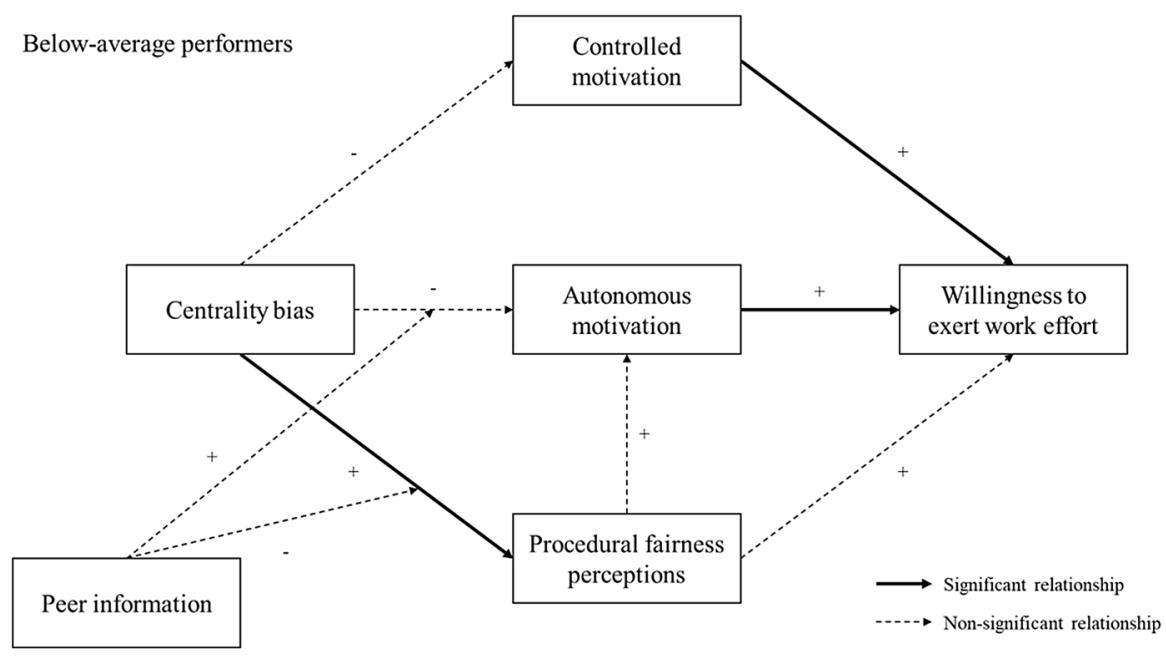

Fig. 4 Summary of findings for below-average performers

bias is - as for above-average performers - negatively associated with both types of motivation, yet these relationships are not statistically significant. Our interpretation concerning controlled motivation is that below-average performers might consider that an increase in effort may mitigate their overvaluation. Yet, the relationship is weaker than for above-average performers, potentially because below-average performers are beneficiaries of the centrality bias and thus have a weaker incentive to decrease their effort. In addition, we find a non-significant relationship between centrality bias and autonomous motivation. A potential explanation for this finding is that centrality bias affects the basic psychological needs-autonomy, competence, and relatedness-differently. Whereas the feelings of competence and relatedness may increase, the feeling of autonomy is likely to decrease. We suggest that these divergent tendencies may explain the non-significant net effect of bias on autonomous motivation.

Eventually, we find that centrality bias is positively and significantly associated with procedural fairness perceptions. We argue that this relationship may be the outcome of a comparison between the reference and the actual evaluation. Interestingly, procedural fairness perceptions are not significantly associated with autonomous motivation for below-average performers. With regard to the moderating effect of peer information, we neither detect a significant moderating effect for the relationship between centrality bias and autonomous motivation nor for the relationship between centrality bias and procedural fairness perceptions. A potential explanation is that individuals do not pay considerable attention to comparisons with their peers when their own evaluation does not appear trustworthy anyway due to the deviation from the objective measure. This finding reinforces the previously outlined conclusion that the psychological mechanisms do not change if the subordinates are aware of the "source" of the bias. 
Taken together, our paper advances our understanding of the psychological mechanisms activated by centrality bias by adopting a broader view that goes beyond an economic perspective. A number of implications arise out of these findings. First, we conclude that transparency due to the provision of peer information does not enhance negative or mitigate positive effects of centrality bias. This finding appears particularly noteworthy in light of a recent study by Bol et al. (2016). They find that the simultaneous increase of information accuracy and outcome transparency may incentivize managers to provide less compressed ratings. In our setting, we regard the provision of peer information as an increase in outcome transparency. Taking the findings by Bol et al. (2016) and ours together, increasing outcome transparency may be an effective design feature of performance measurement systems which include subjectivity, as it may prevent the emergence of centrality bias, but does not aggravate adverse effects if centrality bias occurs after all. Second, these findings complement previous research on relative performance evaluation and tournaments, which indicates that the disclosure of rankings increases the motivational effects on work effort (Luft 2016). Our findings suggest that this effect is not observable when outcome transparency unveils a centrality bias. This conclusion underlines that sensitivity (i.e., sufficient differentiation) in performance evaluation constitutes an important requisite for the motivational effects of peer information detected by prior research. Third, we find that fairness is the only psychological mechanism that is positively affected by centrality bias for below-average performers. Yet, we do not find that fairness is positively associated with the willingness to exert work effort in this context. In summary, we thus conclude that the adoption of a broader perspective going beyond predictions by economic theory explores several simultaneously occurring psychological mechanisms, which in sum, however, do not necessarily result in an increasing willingness to exert work effort. Thus, we detect some asymmetry in the psychological mechanisms as those that lead to adverse effects for above-average performers, do not imply favourable effects on parts of the belowaverage performers.

Our study is subject to a number of limitations. As outlined in the introduction, vignette experiments rely on constructed descriptions of hypothetical situations and capture intentions and attitudes of the participants with regard to these situations. Therefore, vignette experiments appear particularly applicable when researchers are interested in fairness perceptions or motivational processes (Liebe 2017). Nevertheless, we acknowledge that the responses by the participants might be different if they had performed a real-effort task and thus would be more strongly "affected" by an overvaluation or undervaluation. While we cannot rule out this concern entirely, we argue that the high scores on traceability (mean =5.22) suggest that the participants on average put themselves well into the work situation. Moreover, we expect that a stronger involvement and identification with the situation might have stronger psychological implications. Therefore, we expect that our analysis rather tends to underestimate the psychological mechanisms than to overestimate them. Moreover, we acknowledge that we potentially underestimate the influence of peer information as it may play a more pivotal role in real settings, in which employees have personal relationships with their peers. 
In addition, the setting of the case and our manipulation of the variables imply a number of limitations. First, the context of the case is a consulting firm. We chose this context to provide a setting, which the participants can easily understand. In those firms, however, interdependencies between subordinates tend to be stronger because the members of a project team collaborate closely together. At the same time, the working environment tends to be highly competitive. It is possible that corresponding associations have affected the participants' responses. Second, we manipulated performance at two extremes: Participants were either the team member with the lowest or highest overtime hours. However, our findings might differ at intermediate levels of performance. More precisely, it is possible that the associations investigated would be less pronounced for individuals who provide nonextreme levels of performance. Third, we disclosed the ratio of bonus payments, but did not specify the individual amounts. A more differentiated manipulation could carry the risk that varying monetary preferences might confound the findings. Eventually, we acknowledge that the manipulation of the independent variables strengthens causal claims. Nevertheless, we rely on cross-sectional data only, whereas longitudinal data may provide further insights. Against this background, we hope that our study will encourage further research into the psychological mechanisms triggered by centrality bias and their implications for individual and organizational performance. Such research could also consider additional types of bias. In this regard, we put the enrichment of economic theory with insights from the social psychology literature forward to gather a deeper understanding of the behavioural implications of performance evaluation issues.

Open Access This article is distributed under the terms of the Creative Commons Attribution 4.0 International License (http://creativecommons.org/licenses/by/4.0/), which permits unrestricted use, distribution, and reproduction in any medium, provided you give appropriate credit to the original author(s) and the source, provide a link to the Creative Commons license, and indicate if changes were made.

\section{Appendix}

As explained in Sect. 3.2.1, the vignettes comprised two fixed text modules which were common to all participants. The vignettes contained four additional modules from which each participant received one of the two versions outlined in the following.

\section{Introductory text (fixed text module)}

You are working as a consultant with a focus on cost management and management accounting for a renowned consulting firm. You are currently working on a project in an internationally operating company. The project goal is the advancement of the implemented management accounting system. In the context of the project, you are working in a team, which consists of yourself and four colleagues (i.e., consultants) as well as the project team manager. The four colleagues have a similar professional 
qualification and experience as you have and are working as long for the consulting firm as you do. The project team manager is responsible for coordinating the project tasks: He defines working packages that are executed by you and your colleagues.

\section{Description of work climate (manipulated via two different versions of the text module)}

- Positive work climate: The project team manager emphasizes your participation in important decision processes und attaches importance to your opinion. In many situations, you can decide on your own on the time and the way of performing your work, so you do not have to consult the project team manager. For the execution of working packages, you work closely and cooperatively with your colleagues and you feel like an accepted member of the project team.

- Negative work climate: The project manager commonly decides on work-related aspects on his own and rarely asks for your opinion. In many situations, you have to follow preset steps and procedures and you have to consult the project team manager if you want to deviate from them. For the execution of working packages, you consult your colleagues if necessary, with whom you have a distanced relationship.

\section{Description of bonus system (fixed text module)}

Recently, the project team has completed the first of four project milestones. For the first milestone, you and your colleagues have reviewed and evaluated the current management accounting system. As a consultant, you participate financially in the completion of project milestones, i.e., you receive a bonus payment after completion of a milestone. The bonus assessment is the responsibility of the project manager. You are supposed to get remunerated for your work effort. With regard to bonus assessment, the executive board of the consulting firm commends the reliance on the individual overtime hours to the project manager. However, the project manager is not obligated to take the overtime hours as a basis for his assessment, i.e., he is free in his bonus assessment.

\section{Information on the participant's own performance (manipulated via two different versions of the text module)}

- Below-average performance: During the first milestone, you and your colleagues have recorded all overtime hours and forwarded them to the project manager. The project manager has informed you that your overtime hours are below the average overtime hours of the project team members.

- Above-average performance: During the first milestone, you and your colleagues have recorded all overtime hours and forwarded them to the project manager. The 
project manager has informed you that your overtime hours are above the average overtime hours of the project team members.

\section{Information on centrality bias (manipulated via two different versions of the text module)}

- Biased performance evaluation: (i) For the conditions with centrality bias and without provision of peer information, the vignettes contained one of the two figures and annotations shown in Panel A of Fig. 2. (ii) For the conditions with centrality bias and with provision of peer information, the vignettes contained one of the two figures and annotations shown in Panel B of Fig. 2.

- Unbiased performance evaluation: Following the recommendation by the executive board, the project team manager referred to the individual overtime hours for the bonus assessment for you and your colleagues. Consequently, you receive exactly the bonus that you are entitled to according to your overtime hours.

\section{Provision of peer information (manipulated via two different versions of the text module)}

- Provision of peer information: (i) For the conditions with centrality bias and with provision of peer information, the vignettes contained one of the two figures and annotations shown in Panel B of Fig. 2. (ii) For the conditions without centrality bias and with provision of peer information, the vignettes contained one of the two figures and annotations shown in Panel C of Fig. 2.

- No provision of peer information: You do not have any further information regarding the overtime hours of your colleagues.

\section{References}

Adams JS (1965) Inequity in social exchange. Adv Exp Soc Psychol 2:267-299

Aguinis H, Bradley KJ (2014) Best practice recommendations for designing and implementing experimental vignette methodology studies. Org Res Methods 17(4):351-371

Ahn TS, Hwang I, Kim M-I (2010) The impact of performance measure discriminability on ratee incentives. Acc Rev 85(2):389-417

Atzmüller C, Steiner PM (2010) Experimental vignette studies in survey research. Methodol Eur J Res Methods Behav Soc Sci 6(3):128-138

Baker GP, Jensen MC, Murphy KJ (1988) Compensation and incentives: practice vs. theory. J Financ 43(3):593-616

Baron RM, Kenny DA (1986) The moderator-mediator variable distinction in social psychological research: conceptual, strategic, and statistical considerations. J Pers Soc Psychol 51(6):1173-1182

Berger J, Harbring C, Sliwka D (2013) Performance appraisals and the impact of forced distribution-an experimental investigation. Manage Sci 59(1):54-68

Birnberg JG, Shields MD, Young SM (1990) The case for multiple methods in empirical management accounting research (with an illustration from budget setting). J Manage Acc Res 2:33-66 
Bol JC (2008) Subjectivity in compensation contracting. J Acc Lit 24:1-27

Bol JC (2011) The determinants and performance effects of managers' performance evaluation biases. Acc Rev 86(5):1549-1575

Bol JC, Kramer S, Maas VS (2016) How control system design affects performance evaluation compression: the role of information accuracy and outcome transparency. Acc Organ Soc 51:64-73

Bonner SE, Sprinkle GB (2002) The effects of monetary incentives on effort and task performance: theories, evidence, and a framework for research. Acc Organ Soc 27(4-5):303-345

Breuer K, Nieken P, Sliwka D (2013) Social ties and subjective performance evaluations: an empirical investigation. Rev Manag Sci 7(2):141-157

Burney LL, Henle C, Widener SK (2009) A path model examining the relations among strategic performance measurement system characteristics, organizational justice, and extra- and in-role performance. Acc Organ Soc 34(3-4):305-321

Carrell MR, Dittrich JE (1978) Equity theory: the recent literature, methodological considerations, and new directions. Acad Manage Rev 3(2):202-210

Chen Y-L (2014) Determinants of biased subjective performance evaluations: evidence from a Taiwanese public sector organization. Acc Bus Res 44(6):656-675

Cheng MM, Coyte R (2014) The effects of incentive subjectivity and strategy communication on knowledge-sharing and extra-role behaviours. Manage Acc Res 25(2):119-130

Colquitt JA et al (2001) Justice at the millennium: a meta-analytic review of 25 years of organizational justice research. J Appl Psychol 86(3):425-445

Cropanzano R, Folger R (1989) Referent cognitions and task decision autonomy: beyond equity theory. J Appl Psychol 74(2):293-299

Cugueró-Escofet N, Rosanas JM (2013) The just design and use of management control systems as requirements for goal congruence. Manage Acc Res 24(1):23-40

Dai NT, Kuang XJ, Tang G (2018) Differential weighting of objective versus subjective measures in performance evaluation: experimental evidence. Eur Acc Rev 27(1):129-148

Deci EL, Ryan RM (2000) The "what" and "why" of goal pursuits: human needs and the self-determination of behaviour. Psychol Inq 11(4):227-268

Deci EL et al (2001) Need satisfaction, motivation, and well-being in the work organizations of a former Eastern bloc country: a cross-cultural study of self-determination. Pers Soc Psychol Bull 27(8):930-942

Ederhof M (2010) Discretion in bonus plans. Acc Rev 85(6):1921-1949

Eisenhardt KM (1989) Agency theory: an assessment and review. Acad Manage Rev 14(1):57-74

Engellandt A, Riphahn RT (2011) Evidence on incentive effects of subjective performance evaluations. Ind Labor Relat Rev 64(2):241-257

Franco-Santos M, Lucianetti L, Bourne M (2012) Contemporary performance measurement systems: a review of their consequences and a framework for research. Manage Acc Res 23(2):79-119

Frederiksen A, Lange F, Kriechel B (2017) Subjective performance evaluations and employee careers. J Econ Behav Organ 134:408-429

Gagné M, Deci EL (2005) Self-determination theory and work motivation. J Org Behav 26(4):331-362

Gagné M, Forest J (2008) The study of compensation systems through the lens of self-determination theory: reconciling 35 years of debate. Can Psychol 49(3):225-232

Gagné $M$ et al (2010) The motivation at work scale: validation evidence in two languages. Educ Psychol Measur 70(4):628-646

Gagné $M$ et al (2015) The multidimensional work motivation scale: validation evidence in seven languages and nine countries. Eur J Work Org Psychol 24(2):178-196

Gibbs M et al (2004) Determinants and effects of subjectivity in incentives. Acc Rev 79(2):409-436

Goldman BM (2003) The application of referent cognitions theory to legal-claiming by terminated workers: the role of organizational justice and anger. J Manage 29(5):705-728

Golman R, Bhatia S (2012) Performance evaluation inflation and compression. Acc Organ Soc 37(8):534-543

Greenberg J, Ashton-James CE, Ashkanasy NM (2007) Social comparison processes in organizations. Organ Behav Hum Decis Process 102(1):22-41

Hannan RL et al (2013) The effect of relative performance information on performance and effort allocation in a multi-task environment. Acc Rev 88(2):553-575

Hartmann FGH, Slapničar S (2012a) Pay fairness and intrinsic motivation: the role of pay transparency. Int J Hum Resour Man 23(20):4283-4300 
Hartmann FGH, Slapničar S (2012b) The perceived fairness of performance evaluation: the role of uncertainty. Manage Acc Res 23(1):17-33

Hartmann FGH, Naranjo-Gil D, Perego P (2010) The effects of leadership styles and use of performance measures on managerial work-related attitudes. Eur Acc Rev 19(2):275-310

Hayes AF (2013) Introduction to mediation, moderation, and conditional process analysis: a regressionbased approach. The Guilford Press, New York

Hayes AF, Montoya AK, Rockwood NJ (2017) The analysis of mechanisms and their contingencies: pROCESS versus structural equation modeling. Australas Market J 25(1):76-81

Höppe F, Moers F (2011) The choice of different types of subjectivity in CEO annual bonus contracts. Acc Rev 86(6):2023-2046

Ittner CD, Larcker DF, Meyer MW (2003) Subjectivity and the weighting of performance measures: evidence from a balanced scorecard. Acc Rev 78(3):725-758

Kampkötter P, Sliwka D (2016) The complementary use of experiments and field data to evaluate management practices: the case of subjective performance evaluations. J Inst Theor Econ 172(2):364-389

Kampkötter P, Sliwka D (2017) More dispersion, higher bonuses? The role of differentiation in subjective performance evaluations. J Labor Econ (in press)

Kunz J (2015) Objectivity and subjectivity in performance evaluation and autonomous motivation: an exploratory study. Manage Acc Res 27:27-46

Kunz J, Linder S (2012) Organizational control and work effort-another look at the interplay of rewards and motivation. Eur Acc Rev 21(3):591-621

Kunz AH, Pfaff D (2002) Agency theory, performance evaluation, and the hypothetical construct of intrinsic motivation. Acc Organ Soc 27(3):275-295

Lau CM, Tan SLC (2006) The effects of procedural fairness and interpersonal trust on job tension in budgeting. Manage Acc Res 17(2):171-186

Liebe U et al (2017) Using factorial survey experiments to measure attitudes, social norms, and fairness concerns in developing countries. Sociol Methods Res (in press)

Linder S (2016) Fostering strategic renewal: monetary incentives, merit-based promotions, and engagement in autonomous strategic action. J Manag Control 27(2-3):251-280

Luft J (2016) Cooperation and competition among employees: experimental evidence on the role of management control systems. Manage Acc Res 31:75-85

McFarlin DB, Sweeney PD (1992) Distributive and procedural justice as predictors of satisfaction with personal and organizational outcomes. Acad Manage J 35(3):626-637

Moers F (2005) Discretion and bias in performance evaluation: the impact of diversity and subjectivity. Acc Organ Soc 30(1):67-80

Newman AH, Tafkov ID (2014) Relative performance information in tournaments with different prize structures. Acc Organ Soc 39(5):348-361

Prendergast C (1999) The provision of incentives in firms. J Econ Lit 37(1):7-63

Rajan MV, Reichelstein S (2006) Subjective performance indicators and discretionary bonus pools. J Acc Res 44(3):585-618

Tafkov ID (2013) Private and public relative performance information under different compensation contracts. Acc Rev 88(1):327-350

van den Bos K, van Prooijen J-W (2001) Referent cognitions theory: the role of closeness of reference points in the psychology of voice. J Pers Soc Psychol 81(4):616-626

Van den Broeck A et al (2010) Capturing autonomy, competence, and relatedness of the work-related basic need satisfaction scale. J Occup Org Psychol 83(4):981-1002

Van der Stede WA, Chow CW, Lin TW (2006) Strategy, choice of performance measures, and performance. Behav Res Acc 18:185-205

Voußem L, Kramer S, Schäffer U (2016) Fairness perceptions of annual bonus payments: the effects of subjective performance measures and the achievement of bonus targets. Manage Acc Res 30:32-46

Woods A (2012) Subjective adjustments to objective performance measures: the influence of prior performance. Acc Organ Soc 37(6):403-425

Zapata-Phelan CP et al (2009) Procedural justice, interactional justice, and task performance: the mediating role of intrinsic motivation. Organ Behav Hum Dec Process 108(1):93-105 